\title{
Experimental Study on Sandwich Bridge Decks with GFRP Face Sheets and a Foam-Web Core Loaded under Two-Way Bending
}

\author{
Ruili Huo, Weiqing Liu, Li Wan, Yuan Fang, and Lu Wang \\ College of Civil Engineering, Nanjing Tech University, Nanjing 211816, China \\ Correspondence should be addressed to Lu Wang; kevinlwang@hotmail.com
}

Received 30 April 2015; Revised 5 September 2015; Accepted 7 September 2015

Academic Editor: Ana S. Guimarães

Copyright (C) 2015 Ruili Huo et al. This is an open access article distributed under the Creative Commons Attribution License, which permits unrestricted use, distribution, and reproduction in any medium, provided the original work is properly cited.

\begin{abstract}
In recent years, the sandwich bridge decks with GFRP face sheets and light weight material core have been widely used in the world due to their advantages of low cost, high strength to weight ratios, and corrosion resisting. However, as the bridge decks, most of them are used in foot bridges rather than highway bridges because the ultimate bending strength and initial bending stiffness are relatively low. To address this issue and expand the scope of use, a simple and innovative sandwich bridge deck with GFRP face sheets and a foam-web core, manufactured by vacuum assisted resin infusion process, is developed. An experimental study was carried out to validate the effectiveness of this panel for increasing the ultimate bending strength and initial bending stiffness under two-way bending. The effects of face sheet thickness, foam density, web thickness, and web spacing on displacement ductility and energy dissipation were also investigated. Test results showed that, compared to the normal foam-core sandwich decks, an average approximately $657.1 \%$ increase in the ultimate bending strength can be achieved. Furthermore, the bending stiffness, displacement ductility, and energy dissipation can be enhanced by increasing web thickness, web height, and face sheet thickness or decreasing web spacing.
\end{abstract}

\section{Introduction}

In recent years, composite sandwich decks have been used increasingly in the bridge engineering due to their advantages of low cost, high strength to weight ratios, and corrosion resisting. In sandwich decks, low density materials, such as polyurethane foam, paulownia wood, and honeycombs, have been usually employed to be the cores, which are combined with high stiffness face sheets to resist applied loads. The composite face sheets provide major contribution to the bending stiffness while the core provides the major shear stiffness of sandwich decks.

A great number of experimental and analytical studies of sandwich bridge decks with composite face sheets and a foam core under bending have been conducted in the past twenty years. Sharaf et al. [1] tested sandwich wall panels with GFRP face sheets and a foam core under fourpoint bending. The test results indicated that a higher foam density can generate a larger ultimate bending strength and stiffness. Meanwhile, the horizontal slip was affected by foam core toughness. However, the horizontal slip between face sheet and foam core can accelerate the occurrence of interfacial delamination. Romanoff and Varsta $[2,3]$ proposed an analytical model based on the plane frame analysis to predict the bending strength of a web-core sandwich beams and panels. The Clebsch's method was adopted to calculate the deformation of face sheets. Compared to the existing homogenized beam analysis method, the proposed model can achieved more accuracy results. Russo and Zuccarello [4] carried out three-point bending, four-point bending, shear, and flatwise compressive and tensile tests of sandwich decks with PVC foam and polyester mat cores. The test results showed that the ultimate bending strength of decks depended on the failure mode. A numerical model was also established to study the influences of transverse stress on failure modes. In other words, the local buckling failure and delamination failure restrict the practical application of the proposed sandwich decks. Steeves and Fleck $[5,6]$ conducted the experimental and analytical investigations on the collapse mechanisms for simply supported sandwich beams with GFRP face sheets and a PVC foam core loaded in three-point bending. The test results demonstrated that 
failure mode was determined by the beam geometry and the density of the foam core. But the ultimate bending strength and initial stiffness of sandwich panels are small because there are no lattice web or fiber insertions to improve the stiffness of core. Tagarielli et al. [7] investigated the collapse modes of sandwich beams with clamped and simple supports under three-point bending. The results demonstrated that the simply supported beams exhibit a softening postyield response, while the clamped beams perform a hardening behavior due to membrane stretching of the face sheets. Reis [8] and Reis and Rizkalla [9] developed a new type of panels that consisted of GFRP face sheets, foam cores, and through-thickness GFRP insertions. The delamination between GFRP face sheets and core did not occur due to the use of the fiber insertions. Meanwhile, the flatwise compressive strength of proposed panels can be improved sharply. The strength was mainly affected by fiber insertion density, face sheets thickness, and panel height. However, this kind of sandwich decks is used as the foot bridge deck since the ultimate bending strength and initial bending stiffness of sandwich decks are relatively small, which did not satisfy the design requirements of highway bridges. $\mathrm{Zi}$ et al. [10] carried out a bending test to study the performance of a polyurethane foam-filled GFRP bridge deck. The GFRP bridge decks with rectangular holes were manufactured by pultrusion process. The results showed that the bending strength and stiffness were improved significantly compared to the control decks, in which the holes were not filled with foams. In order to avoid the web-flange joint failure, $\mathrm{Zi}$ et al. [11] developed the construction of the web-flange joints during the pultrusion process, in which the fibers of the lattice web were extended to half width of the flanges. Thus, the failure mode was determined by the adhesive strength of interface. Nevertheless, the size of this kind of bridge deck can be restricted due to the use of the pultrusion process. In the meantime, the pultrusion process is not allowed to arrange the GFRP webs in the two directions.

Furthermore, besides the shortcomings summarized in the above literature review, almost all of existing studies focused on investigating the behavior of sandwich panels loaded under one-way bending rather than two-way bending; hence the effects of concentrated loading on the mechanical performance were ignored.

Dawood et al. [12] studied the performance of 3D GFRP sandwich decks with fiber insertions loaded in two-way bending. The results demonstrated that the performance of the decks was governed by the deck height and the shear stiffness of the core. The main failure mode of the decks was local buckling of the deck at the support positions. The influences of face sheet thickness, fiber insertion density, deck height, and aspect ratio on the bending performance of the decks were also investigated. However, the bottom face sheet of deck cannot bring into full play the tensile resistant to the applied loads because of the presence of local buckling effects.

In order to address the mentioned issues, a kind of sandwich bridge deck with GFRP face sheets and foam-web core (GFFW deck), manufactured through vacuum assisted resin infusion process, was developed, as shown in Figure 1. The detailed manufacture procedure, axial compression tests, and one-way bending tests were introduced in our companion papers [13-15]. The test results indicated that, compared to normal sandwich decks, the ultimate bending strength and initial bending stiffness of GFFW decks loaded in four-point bending were enhanced significantly due to the presence of GFRP web. Moreover, this kind of sandwich bridge decks has been applied in some projects, as shown in Figure 2. Figure 2(a) shows a truss bridge with GFFW bridge decks in Shanghai harbor, which allowed the fork lift trucks on the bridge; and Figure 2(b) shows that the GFFW bridge decks were paved on the muddy road as the backing board. In order to thoroughly understand the mechanical behavior of GFFW decks, there is a need to investigate the bending behavior of GFFW decks through experimental evaluation, which is the motivation of this investigation. In this paper, to simulate the two-way bending effects on a deck by a single vehicle tie, the two-way bending test was conducted to study the ultimate bending strength, initial bending stiffness, displacement ductility, and failure modes of the GFFW decks.

\section{Experimental Program}

2.1. Description of Test Specimens and Parameters. In this study, all decks were manufactured by means of vacuum assisted resin infusion process in the Advanced Composite Structures Research Center at Nanjing Tech University. Table 1 shows a summary of the test matrix and designed dimension of decks. Fourteen specimens, involving two control decks (CON60 and CON100) and twelve GFFW decks, were subjected to concentrated load. All decks have identical length $(l)$ and width $(w)$, which were equal to $1000 \mathrm{~mm}$. The other specimens were strengthened by GFRP webs with varying face sheet thickness $\left(t_{s}\right)$, foam density $(\rho)$, web thickness $\left(t_{w}\right)$, and web spacing $(s)$ :

(1) Foam density with either $40 \mathrm{~kg} / \mathrm{m}^{3}, 60 \mathrm{~kg} / \mathrm{m}^{3}$, or $100 \mathrm{~kg} / \mathrm{m}^{3}$, designated as $\mathrm{P} 4, \mathrm{P} 6$, and $\mathrm{P} 1$, respectively.

(2) Decks with either $75 \mathrm{~mm}$ or $125 \mathrm{~mm}$ web spacing, designated as $\mathrm{S} 7$ and $\mathrm{S} 1$, respectively.

(3) Webs with either $1.6 \mathrm{~mm}$ or $3.2 \mathrm{~mm}$ thickness, designated as $\mathrm{W} 1$ and $\mathrm{W} 3$, respectively.

(4) Face sheets with either $1.6 \mathrm{~mm}$ or $3.2 \mathrm{~mm}$ thickness, designated as $\mathrm{T} 1$ and $\mathrm{T} 3$, respectively.

2.2. Material Properties. The composite face sheets were fabricated using E-glass mat and HS-2101-G100 unsaturated polyester resin. The tensile and compressive tests were conducted by the authors in accordance with ASTM D3039/D 3039 M-08 [16] and ASTM D695-10 [17], respectively. The average tensile strength and tensile modulus were $52.7 \mathrm{MPa}$ and $4.9 \mathrm{GPa}$, respectively. The average compressive strength and compressive modulus were $313.7 \mathrm{MPa}$ and $21.7 \mathrm{GPa}$, respectively. Table 2 lists the material properties of the GFRP face sheets.

The PU foams with three different densities $\left(40 \mathrm{~kg} / \mathrm{m}^{3}\right.$, $60 \mathrm{~kg} / \mathrm{m}^{3}$, and $100 \mathrm{~kg} / \mathrm{m}^{3}$ ) were employed in this study. For each of PU foams, total twelve cubic foam core coupons of $50 \mathrm{~mm}$ thick were tested by the authors in compression 


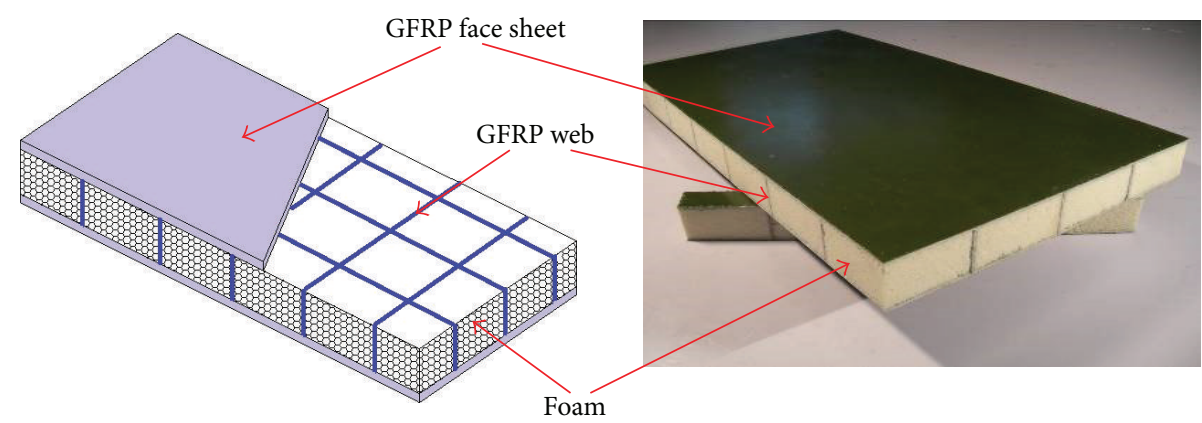

FIGURE 1: The sandwich bridge deck with GFRP face sheets and a foam-web core.

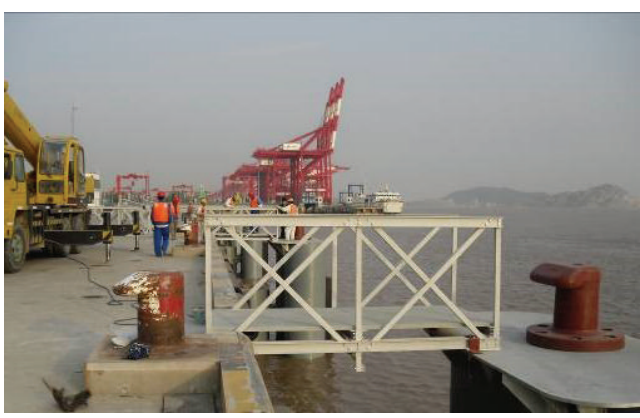

(a)

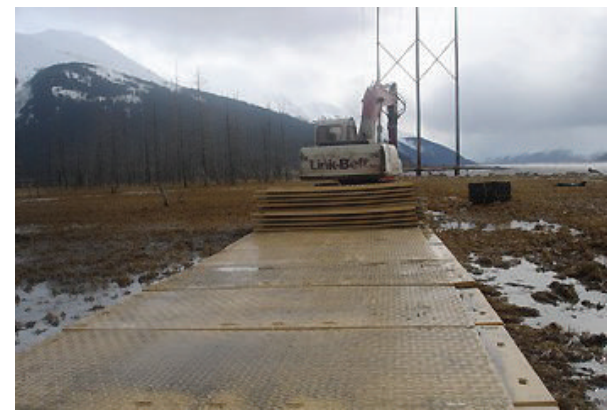

(b)

FIGURE 2: Practical applications of GFFW decks: (a) a truss bridge with GFFW decks and (b) GFFW bridge decks used as the backing board.

TABLE 1: Details of specimens.

\begin{tabular}{lcccccc}
\hline Specimen & $\begin{array}{c}l \\
(\mathrm{~mm})\end{array}$ & $\begin{array}{c}d \\
(\mathrm{~mm})\end{array}$ & $\begin{array}{c}\rho \\
\left(\mathrm{kg} / \mathrm{m}^{3}\right)\end{array}$ & $\begin{array}{c}s \\
(\mathrm{~mm})\end{array}$ & $\begin{array}{c}t_{w} \\
(\mathrm{~mm})\end{array}$ & $\begin{array}{c}t_{s} \\
(\mathrm{~mm})\end{array}$ \\
\hline CON60 & 1000 & 1000 & 60 & - & - & 3.2 \\
CON100 & 1000 & 1000 & 60 & - & - & 3.2 \\
P4S7W1T3 & 1000 & 1000 & 40 & 75 & 1.6 & 3.2 \\
P6S7W1T3 & 1000 & 1000 & 60 & 75 & 1.6 & 3.2 \\
P1S7W1T3 & 1000 & 1000 & 100 & 75 & 1.6 & 3.2 \\
P6S7W1T1 & 1000 & 1000 & 60 & 75 & 1.6 & 1.6 \\
P6S7W1T4 & 1000 & 1000 & 60 & 75 & 1.6 & 4.8 \\
P6S7W3T3 & 1000 & 1000 & 60 & 75 & 3.2 & 3.2 \\
P4S1W1T3 & 1000 & 1000 & 40 & 125 & 1.6 & 3.2 \\
P6S1W1T3 & 1000 & 1000 & 60 & 125 & 1.6 & 3.2 \\
P1S1W1T3 & 1000 & 1000 & 100 & 125 & 1.6 & 3.2 \\
P1S1W1T1 & 1000 & 1000 & 100 & 125 & 1.6 & 1.6 \\
P1S1W1T4 & 1000 & 1000 & 100 & 125 & 1.6 & 4.8 \\
P6S1W4T3 & 1000 & 1000 & 60 & 125 & 4.8 & 3.2 \\
\hline
\end{tabular}

TABLE 2: Material properties of GFRP face sheet.

\begin{tabular}{lc}
\hline & Face sheets \\
\hline Compressive strength $(\mathrm{MPa})$ & 52.7 \\
Compressive modulus $(\mathrm{GPa})$ & 4.9 \\
Tensile strength $(\mathrm{MPa})$ & 313.7 \\
Tensile modulus $(\mathrm{GPa})$ & 21.1 \\
\hline
\end{tabular}

based on ASTM C365-03 [18] and in shear based on ASTM C273/273M-07 [19], using six cubic foam core coupons for each case. Table 3 summarized the measured material properties of foams.

2.3. Test Setup and Instrumentation. The tests were conducted in the Structural Engineering Laboratory at Nanjing Tech University. The decks were supported around all four edges by a stiff steel support which was welded by four steel channels, as shown in Figure 3. A concentrated load was applied using a $500 \mathrm{kN}$ hydraulic actuator acting on a $100 \mathrm{~mm} \times 100 \mathrm{~mm}$ square area at the center of the decks. A 3 $\mathrm{mm}$ thick steel shim and a $2 \mathrm{~mm}$ thick neoprene pad with 100 $\mathrm{mm}$ length and $100 \mathrm{~mm}$ width were placed between actuator and loading area. The load was applied in displacement control at a rate of $2 \mathrm{~mm} / \mathrm{min}$.

To measure the bending deflections of the tested deck, five linear variable displacement transducers (LVDTs) with a stroke of $100 \mathrm{~mm}$ were installed. The arrangement of LVDTs was shown in Figure 4(a). In the meantime, for each deck, five electric resistance strain gauges were pasted on the bottom face sheet to analysis the strain distribution, as shown in Figure 4(b). Moreover, the readings of strain gauges were also used to identify the failure mode of decks.

\section{Experimental Results and Discussion}

The test results, involving the observed failure modes, yield bending strength $\left(P_{y}\right)$, ultimate bending strength $\left(P_{u}\right)$, yield midspan deflection $\left(\Delta_{y}\right)$, ultimate midspan deflection $\left(\Delta_{u}\right)$, 


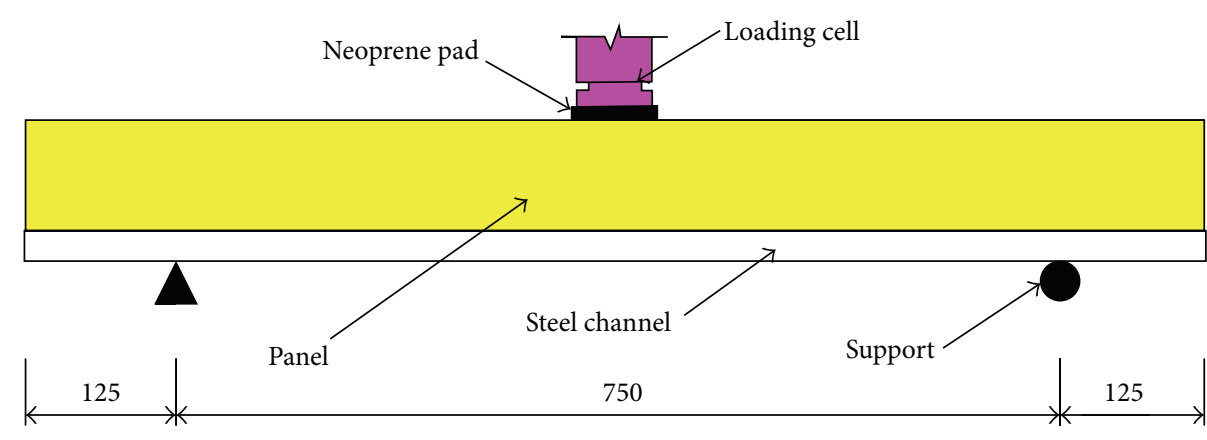

FIGURE 3: Test setup.

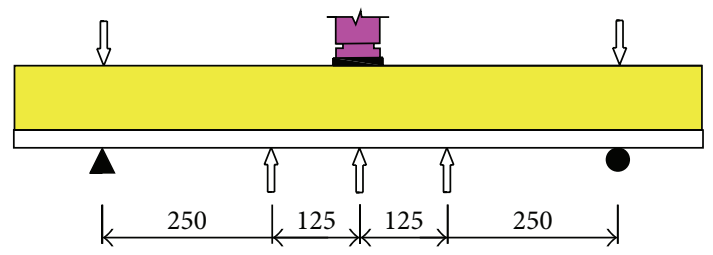

(a)

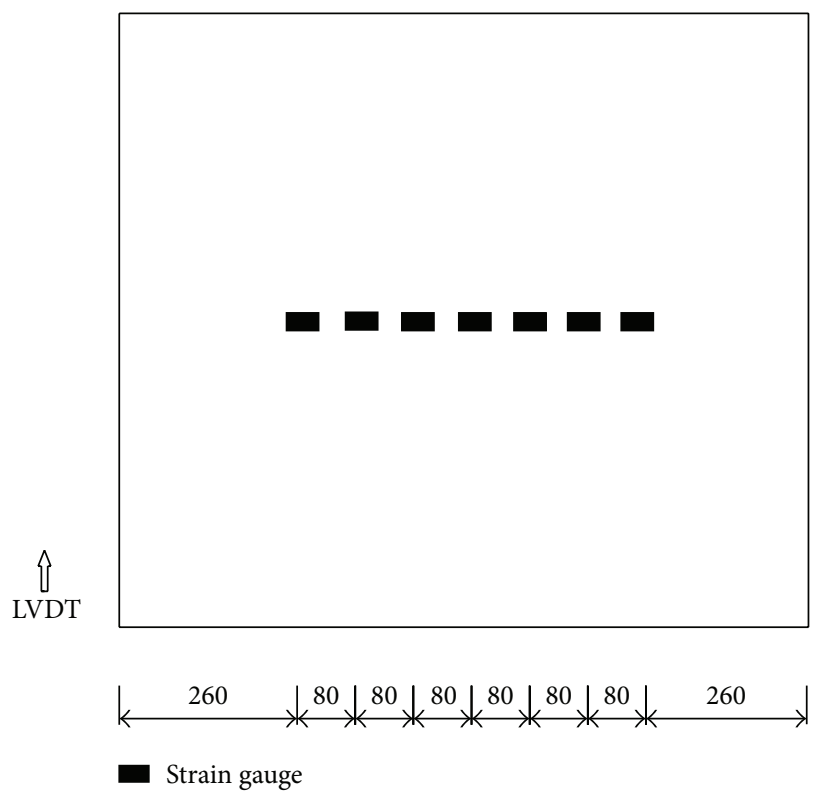

(b)

FIgURE 4: Instrumentation of Specimen P6S7W1T3: (a) LVDT and (b) strain gauge arrangements.

TABLE 3: Material properties of foam.

\begin{tabular}{lccc}
\hline Foam & $40 \mathrm{~kg} / \mathrm{m}^{3}$ & $60 \mathrm{~kg} / \mathrm{m}^{3}$ & $100 \mathrm{~kg} / \mathrm{m}^{3}$ \\
\hline Compressive strength $(\mathrm{MPa})$ & 0.4 & 0.7 & 1.3 \\
Compressive modulus $(\mathrm{MPa})$ & 5.5 & 9.2 & 14.5 \\
Shear strength (MPa) & 0.4 & 0.6 & 0.9 \\
Shear modulus (GPa) & 51.2 & 66.2 & 81.9 \\
\hline
\end{tabular}

initial bending stiffness $\left(K_{e}\right)$, displacement ductility factor $(\eta)$, and energy dissipation factor $(\mu)$, are presented in Table 4.

3.1. Failure Mode. According to the readings of the strain gauges attached to the face sheets, the failure modes of all specimens can be categorised as two types: (1) delamination failure, which occurred in control decks, as shown in Figure 5(a); (2) top face sheet compressive failure, which occurred in GFFW decks, as shown in Figure 5(b). For the first failure mode, when the shear stress in the interface between face sheet and foam core was larger than adhesive shear stress, the delamination phenomenon can be observed. While for the GFFW decks, the delamination failure did not occur because the webs can improve adhesive strength between face sheets and foam cores. For the second failure mode, because the GFRP webs can provide the displacement and rotation restricts for the face sheets, based on the classic elastic stability theory, the calculated critical buckling stress of face sheet is larger than yield stress. Hence, the local buckling failure did not occur. For all GFFW decks, the foam core shear failure and indentation failure did not occur, because the webs can provide resistance to the shear force and meanwhile improve the bending stiffness of GFFW decks.

3.2. Ultimate Bending Strength. Compared with the control decks, the GFFW decks show various degrees of strengthening, which are summarized in Table 4. Compared to Specimens CON60 $\left(\rho=60 \mathrm{~kg} / \mathrm{m}^{3}\right)$, the ultimate bending strength of Specimens P6S7W1T3 and P6S7W3T3 increased by $351.1 \%$ and $657.1 \%$, respectively. Compared to Specimen 
TABLE 4: Two-way bending test results.

\begin{tabular}{lcccccccccc}
\hline Specimen & $\begin{array}{c}P_{y} \\
(\mathrm{kN})\end{array}$ & $\begin{array}{c}P_{u} \\
(\mathrm{kN})\end{array}$ & $\begin{array}{c}\Delta_{y} \\
(\mathrm{~mm})\end{array}$ & $\begin{array}{c}\Delta_{u} \\
(\mathrm{~mm})\end{array}$ & $\begin{array}{c}K_{e} \\
(\mathrm{kN} / \mathrm{mm})\end{array}$ & $\eta$ & $\begin{array}{c}E_{y} \\
(\mathrm{kN} * \mathrm{~mm})\end{array}$ & $\begin{array}{c}E_{u} \\
(\mathrm{kN} * \mathrm{~mm})\end{array}$ & $\begin{array}{c}\mu \\
\text { Failure mode }\end{array}$ \\
\hline CON60 & 18.2 & 18.2 & 16.49 & 16.49 & 1.10 & 1.00 & 150.1 & 150.1 & 1.00 & $\mathrm{D}$ \\
CON100 & 32.1 & 32.1 & 20.43 & 20.43 & 1.57 & 1.00 & 327.9 & 327.9 & 1.00 & $\mathrm{D}$ \\
P4S7W1T3 & 34.6 & 53.2 & 14.2 & 40.9 & 2.44 & 2.88 & 245.7 & 1417.8 & 5.77 & $\mathrm{C}$ \\
P6S7W1T3 & 79.6 & 82.1 & 17.5 & 32.5 & 4.55 & 1.86 & 696.5 & 1909.3 & 2.74 & $\mathrm{C}$ \\
P1S7W1T3 & 88.5 & 108.4 & 12.3 & 21.4 & 7.20 & 1.74 & 544.3 & 1440.2 & 2.65 & $\mathrm{C}$ \\
P6S7W1T1 & 31.8 & 38.9 & 14.5 & 32.1 & 2.19 & 2.21 & 230.6 & 852.7 & 3.70 & $\mathrm{C}$ \\
P6S7W1T4 & 111.2 & 144.2 & 18.9 & 28.2 & 5.88 & 1.49 & 1050.8 & 2238.5 & 2.13 & $\mathrm{C}$ \\
P6S7W3T3 & 130.1 & 137.8 & 10.2 & 15.7 & 12.75 & 1.54 & 663.5 & 1400.2 & 2.11 & $\mathrm{C}$ \\
P4S1W1T3 & 37.2 & 48.5 & 16.7 & 33.2 & 2.23 & 1.99 & 310.6 & 1017.7 & 3.28 & $\mathrm{C}$ \\
P6S1W1T3 & 58.2 & 63.6 & 15.9 & 28.1 & 3.66 & 1.77 & 462.7 & 1205.7 & 2.61 & $\mathrm{C}$ \\
P1S1W1T3 & 71.4 & 86.7 & 13.9 & 23.1 & 5.14 & 1.66 & 496.2 & 1223.5 & 2.47 \\
P1S1W1T1 & 32.3 & 40.9 & 17.5 & 31.9 & 1.85 & 1.82 & 282.6 & 809.7 & 2.86 & $\mathrm{C}$ \\
P1S1W1T4 & 102.3 & 130.9 & 9.78 & 14.3 & 10.46 & 1.46 & 500.3 & 1027.3 & 2.05 & $\mathrm{C}$ \\
P6S1W4T3 & 105.7 & 126.9 & 11.2 & 16.5 & 9.44 & 1.47 & 591.9 & 1208.3 & 2.04
\end{tabular}

Note: " $\mathrm{D}$ " is delamination failure and " $\mathrm{C}$ " is top face sheet compressive failure.

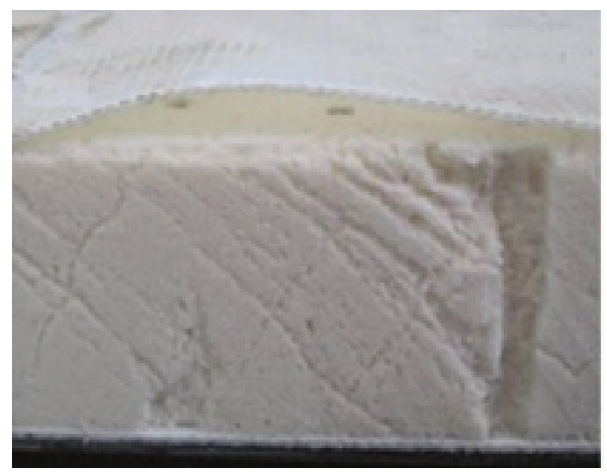

(a)

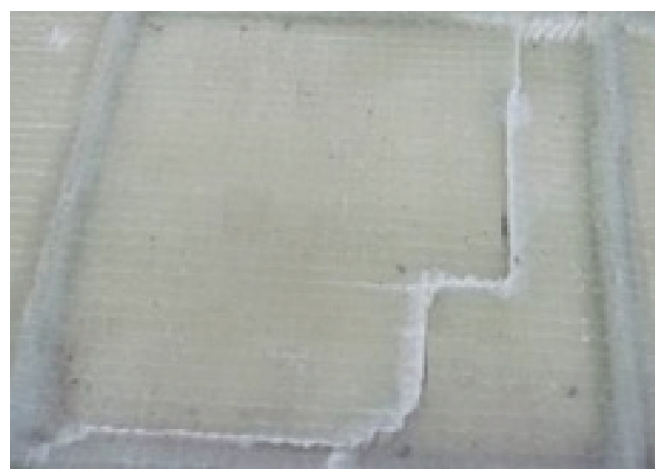

(b)

FIGURE 5: Failure modes (a) delamination of Specimen CON60 and (b) face sheet rupture of Specimen P6S7W1T1.

CON100 $\left(\rho=100 \mathrm{~kg} / \mathrm{m}^{3}\right)$, the ultimate bending strength of Specimens P1S7W1T3 and P1S1W1T3 increased by $237.7 \%$ and $170.1 \%$, respectively. Hence, it is evident that the improvement in ultimate bending strength of GFFW decks is significantly due to the presence of GFRP webs.

Figures 6(a) and 6(b) show the influence of face sheet thickness $\left(t_{s}\right)$ on the ultimate bending strength of GFFW decks. As shown in Figure 6(a), under the same foam density $\left(\rho=60 \mathrm{~kg} / \mathrm{m}^{3}\right)$, web spacing $(s=75 \mathrm{~mm})$, and web thickness $\left(t_{w}=1.6 \mathrm{~mm}\right)$, when the face sheet thickness was $1.6 \mathrm{~mm}$, the ultimate bending strength of Specimen P6S7W1T1 was the smallest, which was equal to $38.9 \mathrm{kN}$. While the face sheet thickness increased to $4.8 \mathrm{~mm}$, the ultimate bending strength of Specimen P6S7W1T4 was the largest, which increased by $270.7 \%$ compared to that of Specimen P6S7W1T1. As shown in Figure 6(b), under the same foam density ( $\rho=$ $\left.100 \mathrm{~kg} / \mathrm{m}^{3}\right)$, web spacing $(s=125 \mathrm{~mm})$, and web thickness $\left(t_{w}=1.6 \mathrm{~mm}\right)$, when the face sheet thickness was $1.6 \mathrm{~mm}$, the ultimate bending strength of Specimen P1S1W1T1 was the smallest, which was equal to $40.9 \mathrm{kN}$. While the face sheet thickness increased to $4.8 \mathrm{~mm}$, the ultimate bending strength of Specimen P1S1W1T4 was the largest, which increased by $220.0 \%$ compared to that of Specimen P1S1W1T1.

Figures 7(a) and 7(b) show the influence of foam density $(\rho)$ on the ultimate bending strength of GFFW decks. Compared to specimens P4S7W1T3 $\left(t_{s}=3.2 \mathrm{~mm}, s=75 \mathrm{~mm}\right.$, and $\left.t_{w}=1.6 \mathrm{~mm}\right)$ and P4S1W1T3 $\left(t_{s}=3.2 \mathrm{~mm}, s=125 \mathrm{~mm}\right.$, and $t_{w}=1.6 \mathrm{~mm}$ ) with $40 \mathrm{~kg} / \mathrm{m}^{3}$ foam density, the ultimate bending strength of specimens P6S7W1T3 $\left(t_{s}=1.6 \mathrm{~mm}\right.$, $s=75 \mathrm{~mm}$, and $\left.t_{w}=1.6 \mathrm{~mm}\right)$ and P6S1W1T3 $\left(t_{s}=1.6 \mathrm{~mm}\right.$, $s=75 \mathrm{~mm}$, and $t_{w}=1.6 \mathrm{~mm}$ ) with $60 \mathrm{~kg} / \mathrm{m}^{3}$ foam density increased by $54.3 \%$ and $103.8 \%$, respectively, and the ultimate bending strength of specimens P1S7W1T3 $\left(t_{s}=1.6 \mathrm{~mm}\right.$, $s=75 \mathrm{~mm}$, and $\left.t_{w}=1.6 \mathrm{~mm}\right)$ and P1S1W1T3 $\left(t_{s}=1.6 \mathrm{~mm}\right.$, $s=75 \mathrm{~mm}$, and $t_{w}=1.6 \mathrm{~mm}$ ) with $100 \mathrm{~kg} / \mathrm{m}^{3}$ foam density increased by $31.1 \%$ and $78.8 \%$, respectively.

Figures 8(a) and 8(b) show the influence of web thickness $\left(t_{w}\right)$ on the ultimate bending strength of GFFW decks. Compared to Specimen P6S7W1T3 $\left(t_{s}=3.2 \mathrm{~mm}, s=75 \mathrm{~mm}\right.$, and $\rho=60 \mathrm{~kg} / \mathrm{m}^{3}$ ) with $1.6 \mathrm{~mm}$ thick web thickness, 


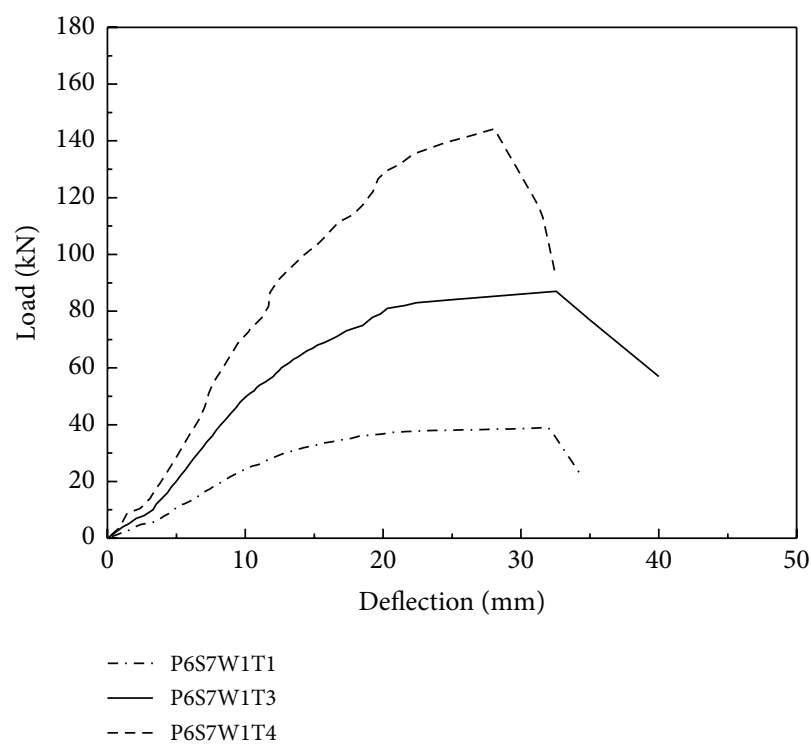

(a)

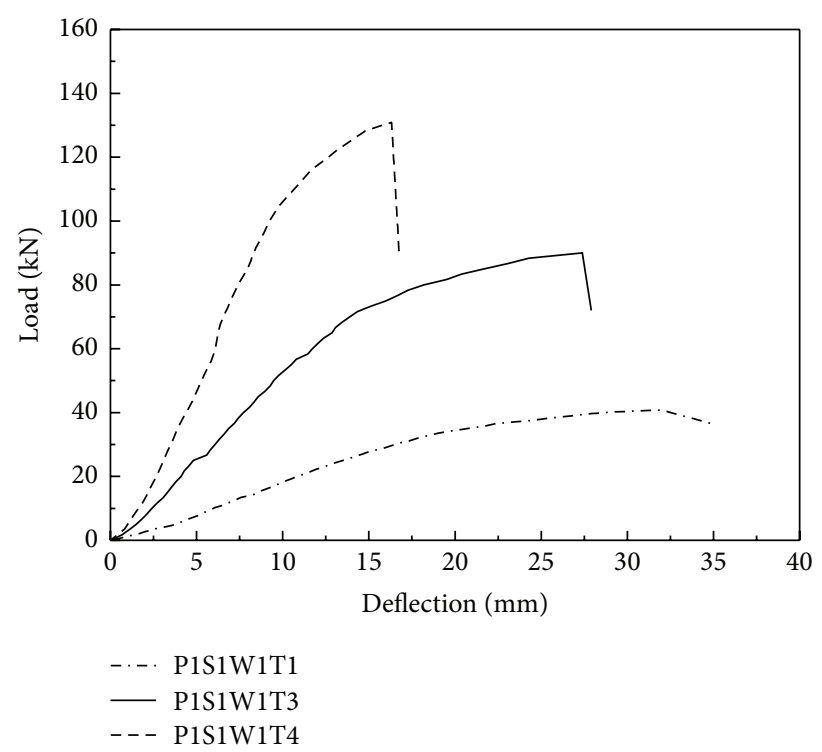

(b)

Figure 6: The influence of face sheet thickness: (a) $t_{w}=1.6 \mathrm{~mm}, s=75 \mathrm{~mm}$, and $\rho=60 \mathrm{~kg} / \mathrm{m}^{3}$ and (b) $t_{w}=1.6 \mathrm{~mm}, s=125 \mathrm{~mm}$, and $\rho=$ $100 \mathrm{~kg} / \mathrm{m}^{3}$.

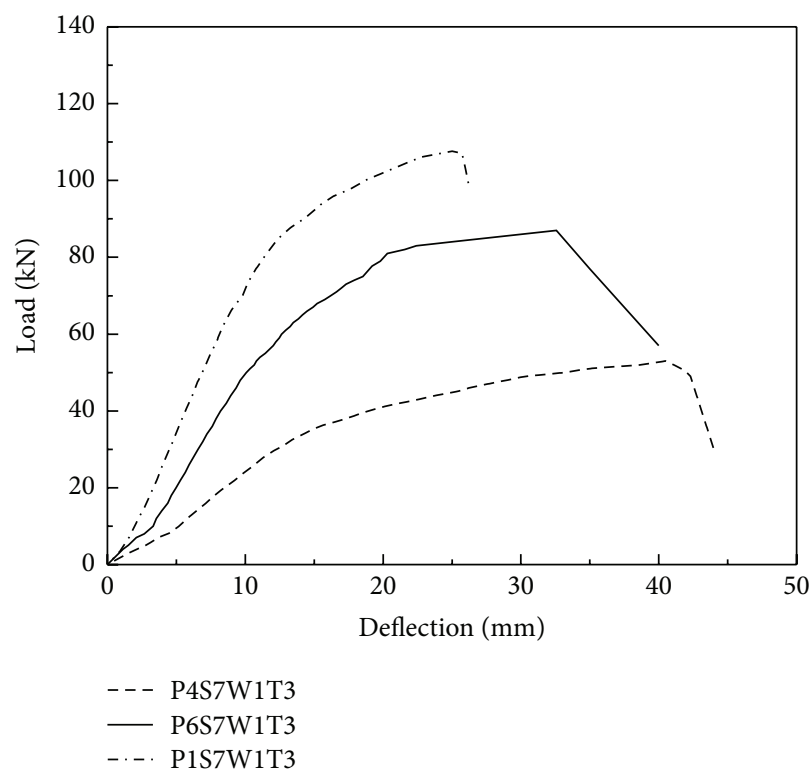

(a)

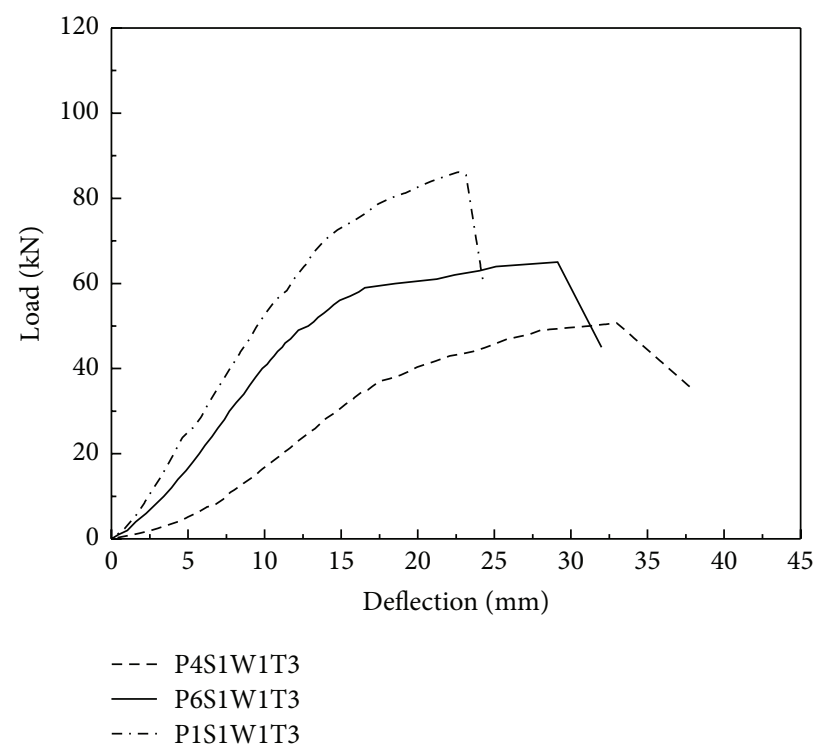

(b)

Figure 7: The influence of foam density: (a) $t_{s}=3.2 \mathrm{~mm}, s=75 \mathrm{~mm}$, and $t_{w}=1.6 \mathrm{~mm}$ and (b) $t_{s}=3.2 \mathrm{~mm}, s=125 \mathrm{~mm}$, and $t_{w}=1.6 \mathrm{~mm}$.

the ultimate bending strength of Specimen P6S7W3T3 with $3.2 \mathrm{~mm}$ web thickness increased by $67.8 \%$. Compared to Specimen P6S1W1T3 $\left(t_{s}=3.2 \mathrm{~mm}, s=125 \mathrm{~mm}\right.$, and $\rho=$ $60 \mathrm{~kg} / \mathrm{m}^{3}$ ) with $1.6 \mathrm{~mm}$ thick web thickness, the ultimate bending strength of Specimen P6S1W4T3 with $4.8 \mathrm{~mm}$ web thickness increased by $99.5 \%$.

Figures 9(a) and 9(b) show the influence of web spacing $(s)$ on the ultimate bending strength of GFFW decks. Under the conditions of $t_{s}=3.2 \mathrm{~mm}, t_{w}=1.6 \mathrm{~mm}$, and $\rho=60 \mathrm{~kg} / \mathrm{m}^{3}$, the ultimate bending strength of Specimen P6S7W1T3
( $s=75 \mathrm{~mm}$ ) was $83.3 \mathrm{kN}$, which was $29.1 \%$ larger than that of Specimen P6S1W1T3 $(s=125 \mathrm{~mm})$. Under the conditions of $t_{s}=3.2 \mathrm{~mm}, t_{w}=1.6 \mathrm{~mm}$, and $\rho=100 \mathrm{~kg} / \mathrm{m}^{3}$, the ultimate bending strength of Specimen P1S7W1T3 $(s=75 \mathrm{~mm})$ was $83.3 \mathrm{kN}$, which was $25.0 \%$ larger than that of Specimen P1S1W1T3 ( $s=125 \mathrm{~mm})$.

Hence, a larger face sheet thickness, foam density, and web thickness can lead to a higher ultimate bending strength of the GFFW decks, while a larger web spacing can lead to a lower ultimate bending strength of the GFFW decks. 


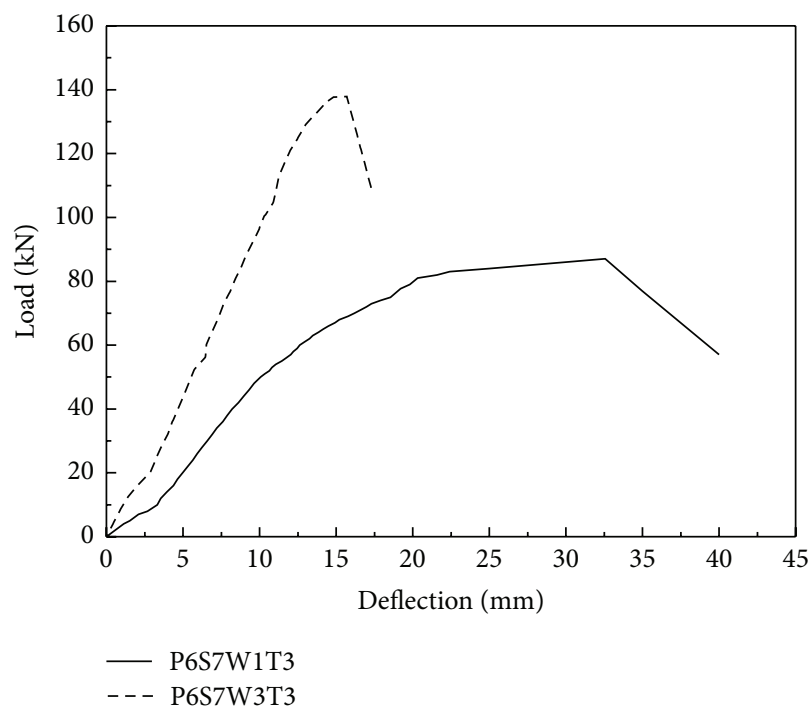

(a)

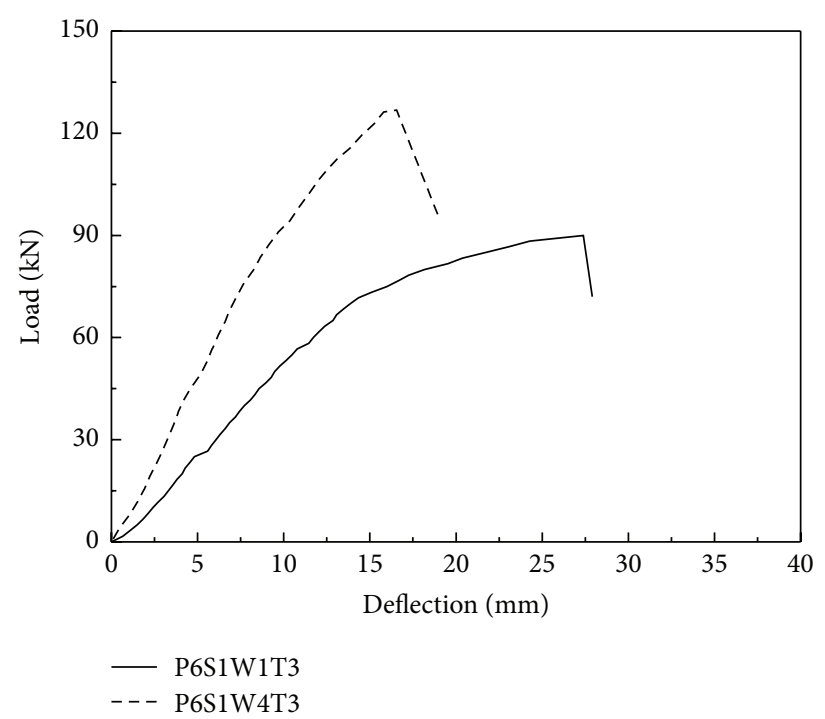

(b)

Figure 8: The influence of web thickness: (a) $t_{s}=3.2 \mathrm{~mm}, s=75 \mathrm{~mm}$, and $\rho=60 \mathrm{~kg} / \mathrm{m}^{3}$ and (b) $t_{s}=3.2 \mathrm{~mm}, s=125 \mathrm{~mm}$, and $\rho=60 \mathrm{~kg} / \mathrm{m}^{3}$.

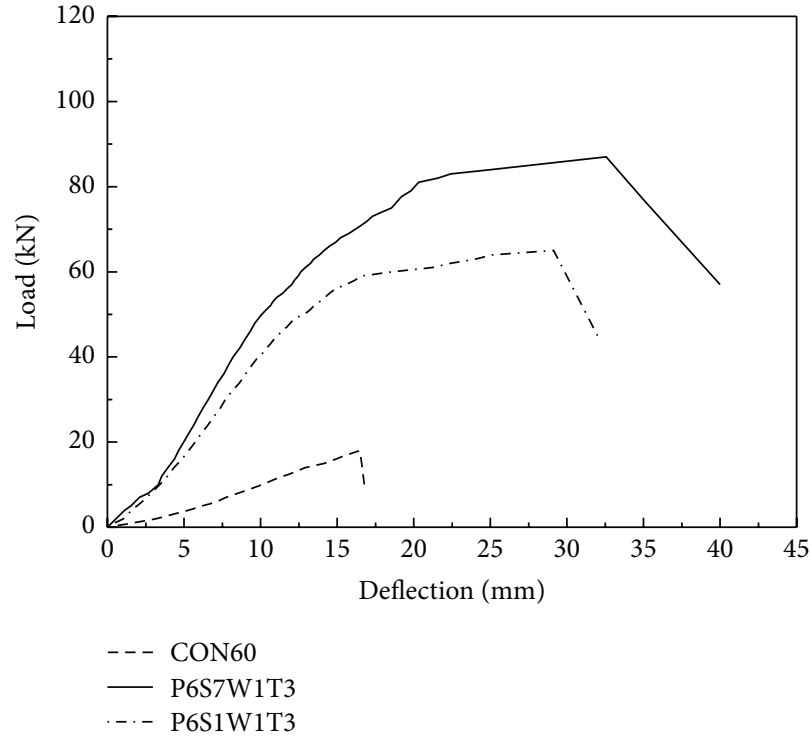

(a)

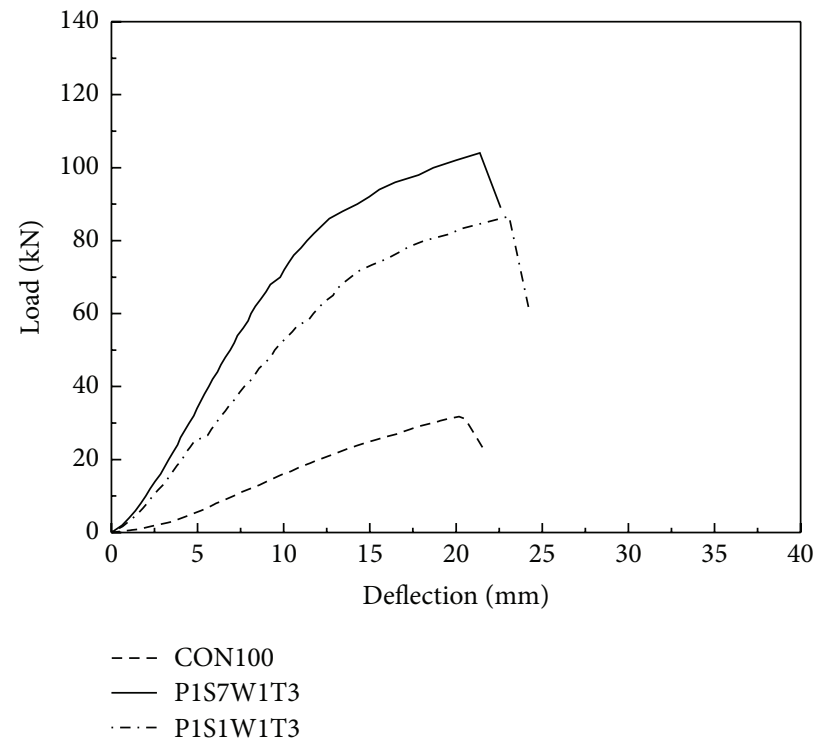

(b)

Figure 9: The influence of web spacing: (a) $t_{s}=3.2 \mathrm{~mm}, \rho=60 \mathrm{~kg} / \mathrm{m}^{3}$, and $t_{w}=1.6 \mathrm{~mm}$ and (b) $t_{s}=3.2 \mathrm{~mm}, \rho=100 \mathrm{~kg} / \mathrm{m}^{3}$, and $t_{w}=1.6 \mathrm{~mm}$.

3.3. Initial Bending Stiffness. The initial bending stiffness of a $\operatorname{deck}\left(K_{e}\right)$ is determined by

$$
K_{e}=\frac{P_{y}}{\Delta_{y}},
$$

where $P_{y}$ and $\Delta_{y}$ are the yield strength of a deck and corresponding yield deflection, respectively (see Figure 10).

Figure 11(a) shows the influences of GFRP face sheet thickness on the initial bending stiffness of GFFW decks. Compared to Specimen P6S7W1T1 $\left(K_{e}=2.19 \mathrm{kN} / \mathrm{mm}\right)$ with
$1.6 \mathrm{~mm}$ face sheet thickness, $K_{e}$ of Specimens P6S7W1T3 $\left(t_{s}=\right.$ $3.2 \mathrm{~mm})$ and P6S7W1T4 $\left(t_{s}=4.8 \mathrm{~mm}\right)$ increased by $107.7 \%$ and $168.7 \%$, respectively. Compared to Specimen P1S1W1T1 $\left(K_{e}=1.85 \mathrm{kN} / \mathrm{mm}\right)$ with $1.6 \mathrm{~mm}$ face sheet thickness, $K_{e}$ of Specimens P1S1W1T3 $\left(t_{s}=3.2 \mathrm{~mm}\right)$ and P1S1W1T4 $\left(t_{s}=\right.$ $4.8 \mathrm{~mm}$ ) increased by $97.9 \%$ and $465.4 \%$, respectively. Thus, using thicker GFRP face sheet can improve the initial bending stiffness of decks significantly.

Figure 11(b) shows the influences of foam density on the initial bending stiffness of GFFW decks. Compared to Specimen P4S7W1T3 $\left(K_{e}=2.44 \mathrm{kN} / \mathrm{mm}\right)$ with $40 \mathrm{~kg} / \mathrm{m}^{3}$ 


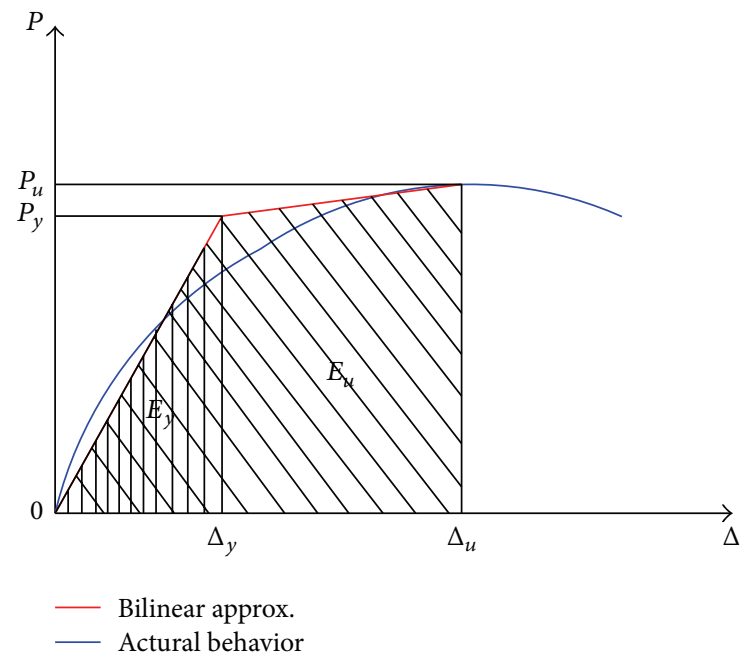

Figure 10: The idealised load-midspan deflection curve.

foam density, $K_{e}$ of Specimens P6S7W1T3 $\left(\rho=60 \mathrm{~kg} / \mathrm{m}^{3}\right)$ and P1S7W1T3 $\left(\rho=100 \mathrm{~kg} / \mathrm{m}^{3}\right)$ were $4.55 \mathrm{kN} / \mathrm{mm}$ and $7.20 \mathrm{kN} / \mathrm{mm}$, respectively, which were $86.4 \%$ and $194.9 \%$ greater than that of Specimen P4S7W1T3. Compared to Specimen P4S1W1T3 $\left(K_{e}=2.23 \mathrm{kN} / \mathrm{mm}\right)$ with $40 \mathrm{~kg} / \mathrm{m}^{3}$ foam density, $K_{e}$ of Specimens P6S1W1T3 $\left(\rho=60 \mathrm{~kg} / \mathrm{m}^{3}\right)$ and P1S1W1T3 $\left(\rho=100 \mathrm{~kg} / \mathrm{m}^{3}\right)$ were $3.66 \mathrm{kN} / \mathrm{mm}$ and $5.14 \mathrm{kN} / \mathrm{mm}$, respectively, which were $64.1 \%$ and $130.3 \%$ greater than that of Specimen P4S7W1T3. The foam with larger density also behaves stiffer. Therefore, a larger foam density can generate a larger bending stiffness.

Figure 11(c) shows the influences of web thickness on the initial bending stiffness of GFFW decks. Compared to specimens P6S7W1T3 $\left(t_{s}=3.2 \mathrm{~mm}, s=75 \mathrm{~mm}\right.$, and $\left.\rho=60 \mathrm{~kg} / \mathrm{m}^{3}\right)$ and P6S1W1T3 $\left(t_{s}=3.2 \mathrm{~mm}, s=125 \mathrm{~mm}\right.$, and $\left.\rho=60 \mathrm{~kg} / \mathrm{m}^{3}\right)$ with $1.6 \mathrm{~mm}$ web thickness, $K_{e}$ of specimens P6S7W3T3 with $3.2 \mathrm{~mm}$ web thickness and P6S1W4T3 with $4.8 \mathrm{~mm}$ web thickness increased by $180.4 \%$ and $157.8 \%$, respectively, which were equal to $12.75 \mathrm{kN} / \mathrm{mm}$ and $9.44 \mathrm{kN} / \mathrm{mm}$. Because increasing the web thickness can result in a larger ratio of the volume of web to foam, which can increase the equivalent Young's modulus according to (3), a larger ultimate bending strength of GFFW deck can be achieved.

Figure 11(d) shows the influences of web spacing on the initial bending stiffness of GFFW decks. For Specimens P6S7W1T3 and P1S7W1T3 with $75 \mathrm{~mm}$ web spacing, $1.6 \mathrm{~mm}$ web thickness, $3.2 \mathrm{~mm}$ face sheet thickness, and $60 \mathrm{~kg} / \mathrm{m}^{3}$ foam density, $K_{e}$ of them were $4.55 \mathrm{kN} / \mathrm{mm}$ and $7.20 \mathrm{kN} / \mathrm{mm}$, respectively, which were $24.3 \%$ and $40.1 \%$ greater than those of Specimens P6S1W1T3 and P1S1W1T3 with $125 \mathrm{~mm}$ web spacing, $1.6 \mathrm{~mm}$ web thickness, $3.2 \mathrm{~mm}$ face sheet thickness, and $60 \mathrm{~kg} / \mathrm{m}^{3}$ foam density. Decreasing web spacing can increase the ratio of the volume of web to foam, which was the same as the thicker webs. Hence, the equivalent Young's modulus can be improved. Furthermore, the larger ratio of the volume of web to foam can enhance the shear capacity and face sheet/core adhesive strength of panels. Therefore, smaller web spacing leads to a higher ultimate bending strength.
3.4. Improvements in Displacement Ductility. The displacement ductility factor $(\eta)$ is adopted to evaluate the ductility performance of the specimens, which is given by

$$
\eta=\frac{\Delta_{u}}{\Delta_{y}},
$$

where $\Delta_{u}$ is the ultimate deflection corresponding to the ultimate bending strength (see Figure 12).

As summarized in Table 4, the displacement ductility factors range from 1.0 (for control specimens) to 2.88 (for Specimen P4S7W1T3). As shown in Figure 12(a), compared to Specimens P6S7W1T1 $(\eta=2.21)$ and P1S1W1T1 $(\eta=1.82)$ with $1.6 \mathrm{~mm}$ face sheet thickness, $\eta$ of Specimens P6S7W1T3 $(\eta=1.86)$ and P1S1W1T3 $(\eta=1.66)$ with $3.2 \mathrm{~mm}$ face sheet thickness decreased by $18.8 \%$ and $9.6 \%$, respectively; $\eta$ of Specimens P6S7W1T4 $(\eta=1.49)$ and P1S1W1T4 $(\eta=1.46)$ with $4.8 \mathrm{~mm}$ face sheet thickness decreased by $48.3 \%$ and $24.7 \%$, respectively. Hence, using thinner GFRP face sheet can effectively improve the displacement ductility of GFFW decks.

In terms of the influence of foam density on the displacement ductility (see Figure 12(b)), compared to Specimen P1S7W1T3 $(\eta=1.46)$ with $100 \mathrm{~kg} / \mathrm{m}^{3}$ foam density, $\eta$ of Specimens P4S7W1T3 with $40 \mathrm{~kg} / \mathrm{m}^{3}$ foam density and P6S7W1T3 with $60 \mathrm{~kg} / \mathrm{m}^{3}$ foam density increased by $65.5 \%$ and $6.7 \%$, respectively, which were equal to 2.88 and 1.86 . Compared to Specimen P1S1W1T3 $(\eta=1.66)$ with $100 \mathrm{~kg} / \mathrm{m}^{3}$ foam density, $\eta$ of Specimens P4S1W1T3 with $40 \mathrm{~kg} / \mathrm{m}^{3}$ foam density and P6S1W1T3 with $60 \mathrm{~kg} / \mathrm{m}^{3}$ foam density increased by $19.8 \%$ and $6.5 \%$, respectively, which were equal to 1.99 and 1.77. Therefore, the displacement ductility factor can become smaller with the increase in the foam density.

As shown in Figure 12(c), using thicker web $t_{w}=3.2 \mathrm{~mm}$ for strengthening Specimen P6S7W3T3 and $t_{w}=4.8 \mathrm{~mm}$ for strengthening Specimen P6S1W4T3 instead of thinner web $\left(t_{w}=1.6 \mathrm{~mm}\right)$ for Specimens P6S7W1T3 and P6S7W1T3, $\eta$ of P6S7W3T3 and P6S1W4T3 were almost 85\% when compared with their counterpart. Hence, the thinner web can result in better ductility of decks. For the influence of web spacing on the displacement ductility (see Figure 12(d)), compared to Specimens P6S7W1T3 and P1S7W1T3 $(s=75 \mathrm{~mm}), \eta$ of Specimens P6S1W1T3 and P1S1W1T3 with $125 \mathrm{~mm}$ web spacing decreased by $4.8 \%$ and $4.5 \%$, respectively. Thus, the displacement ductility of GFFW decks can be affected by web spacing slightly.

3.5. Energy Dissipation. The energy ductility coefficient $(\mu)$ was much more reasonable to evaluate the postyield deformation of the decks [14], which can be expressed as

$$
\mu=\frac{E_{u}}{E_{y}},
$$

where the yield energy $E_{y}$ is the triangular area under the load-midspan deflection curve and the ultimate energy $E_{u}$ is the total area under the load-midspan deflection curve (see Figure 10). 


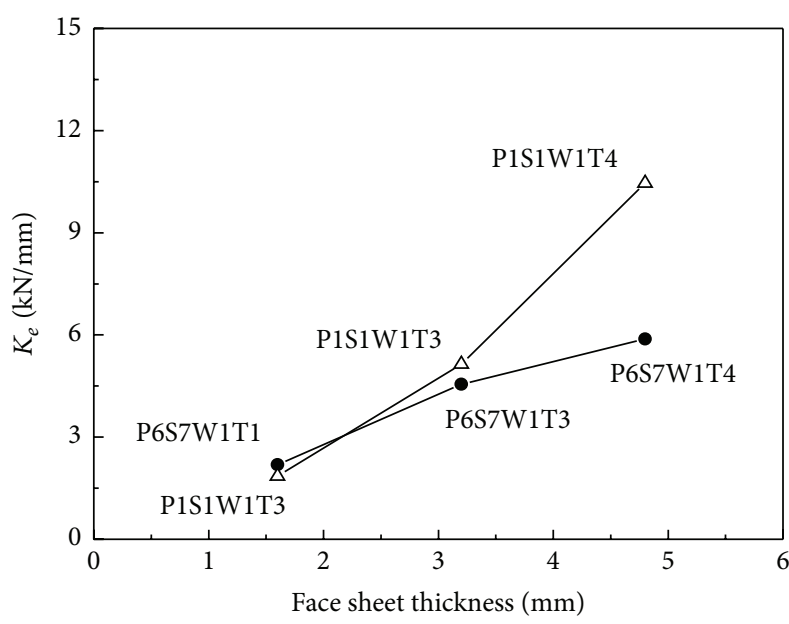

(a)

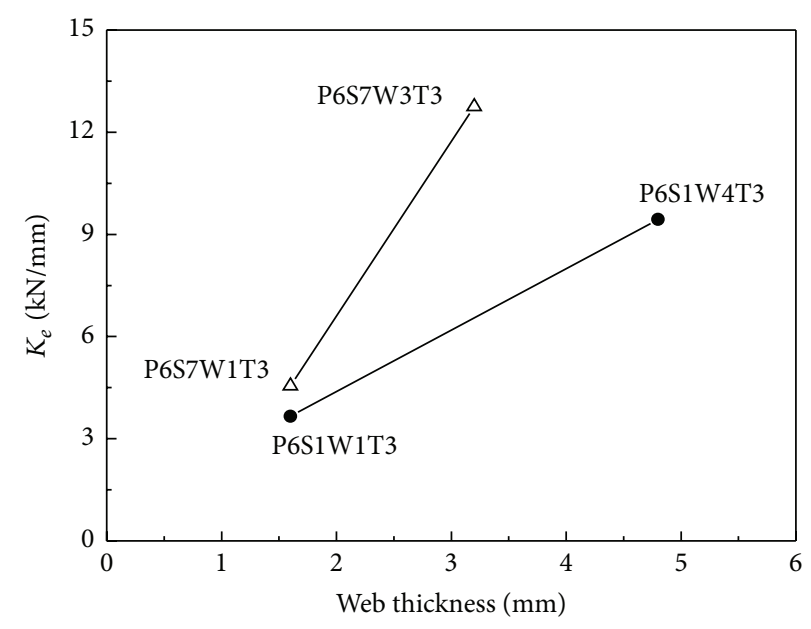

(c)

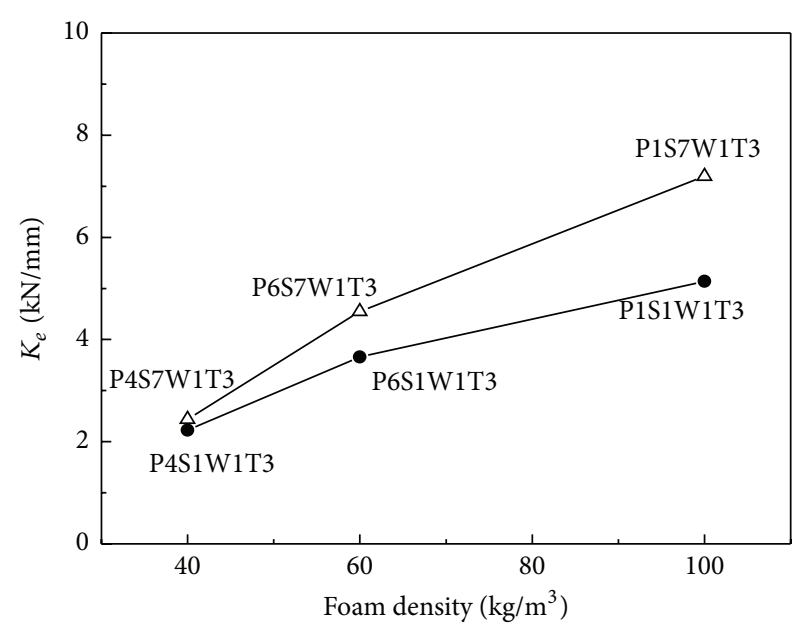

(b)

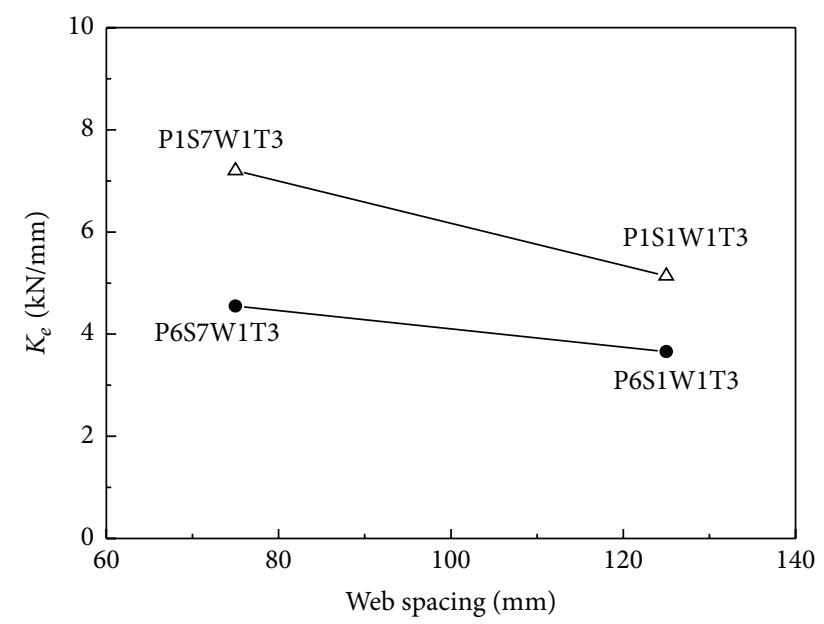

(d)

FIGURE 11: Initial bending stiffness: (a) the influence of face sheet thickness, (b) the influence of foam density, (c) the influence of web thickness, and (d) the influence of web thickness.

As summarized in Table 4, the energy ductility coefficients of control specimens are the smallest, which were nearly equal to 1.0. Figure 13(a) shows the influence of face sheet thickness on the energy ductility coefficient of decks. Comparison of the values of $\mu$ of Specimens P6S7W1T1, P6S7W1T3, and P6S7W1T4 indicates that increasing the skin thickness from $1.6 \mathrm{~mm}$ to $4.8 \mathrm{~mm}$ decreased the energy ductility coefficient of the deck by $25.9 \%$ and $42.4 \%$ relative to $\mu$ of Specimen P6S7W1T1. Similarly, comparison of the values of $\mu$ of Specimens P1S1W1T1, P1S1W1T3, and P1S1W1T4 shows that increasing the skin thickness from $1.6 \mathrm{~mm}$ to $4.8 \mathrm{~mm}$ decreased the energy ductility coefficient of the deck by $13.8 \%$ and $28.2 \%$ relative to $\mu$ of Specimen P1S1W1T1. Figure 13(b) shows the influence of foam density on the energy ductility coefficient of decks. Compared to Specimen P1S7W1T3 ( $\mu=$ 2.65 ) with $100 \mathrm{~kg} / \mathrm{m}^{3}$ foam density, $\mu$ of Specimens P4S7W1T3 with $40 \mathrm{~kg} / \mathrm{m}^{3}$ foam density and P6S7W1T3 with $60 \mathrm{~kg} / \mathrm{m}^{3}$ foam density were equal to 5.77 and 2.74 , which increased by $117.8 \%$ and $3.4 \%$, respectively. Compared to Specimen P1S1W1T3 $(\mu=2.47)$ with $100 \mathrm{~kg} / \mathrm{m}^{3}$ foam density, $\mu$ of Specimens P4S1W1T3 with $40 \mathrm{~kg} / \mathrm{m}^{3}$ foam density and P6S1W1T3 with $60 \mathrm{~kg} / \mathrm{m}^{3}$ foam density were equal to 3.28 and 2.61 , which increased by $32.6 \%$ and $5.5 \%$, respectively. Turning to the influence of web thickness on the energy ductility coefficients, as shown in Figure 13(c), compared to Specimens P6S7W1T3 $(\mu=2.74)$ and P6S1W1T3 $(\mu=2.61)$ with $1.6 \mathrm{~mm}$ web thickness, $\mu$ of Specimens P6S7W3T3 with $3.2 \mathrm{~mm}$ web thickness and P6S1W4T3 with $4.8 \mathrm{~mm}$ web thickness were equal to 2.11 and 2.04 , which slightly decreased by $23.0 \%$ and 21.8\%, respectively. As shown in Figure 13(d), Although the web spacing of Specimens P6S1W1T3 and P1S1W1T3 was nearly 1.7 times of that of Specimens P6S7W1T3 and P1S7W1T3 $(s=75 \mathrm{~mm})$, the energy ductility coefficients were $4.9 \%$ and $6.8 \%$ smaller than that of Specimens P6S7W1T3 and P1S7W1T3, which were equal to 2.74 and 2.65 , respectively. Therefore, the test results indicate that the energy ductility 


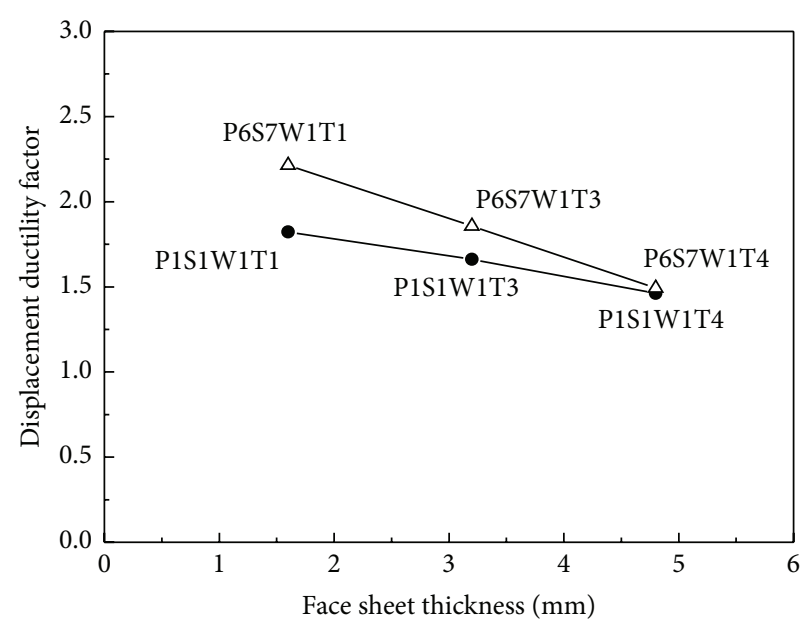

(a)

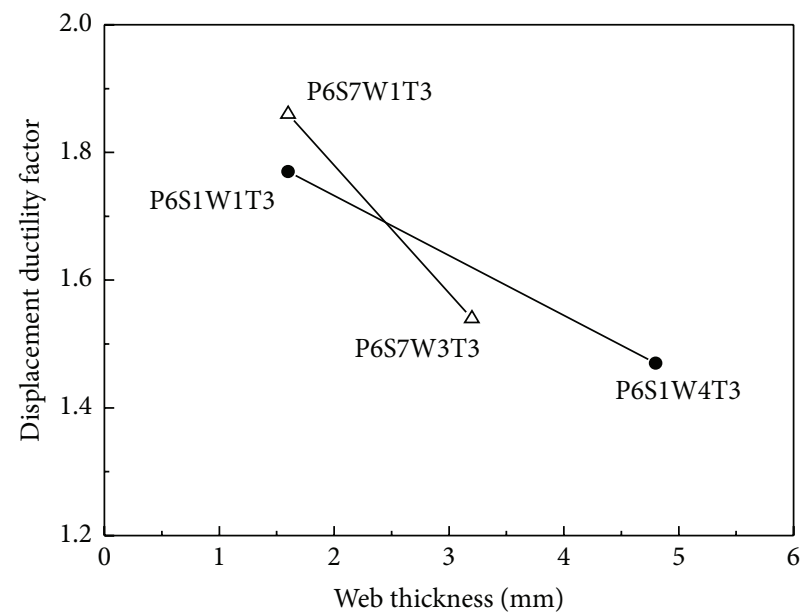

(c)

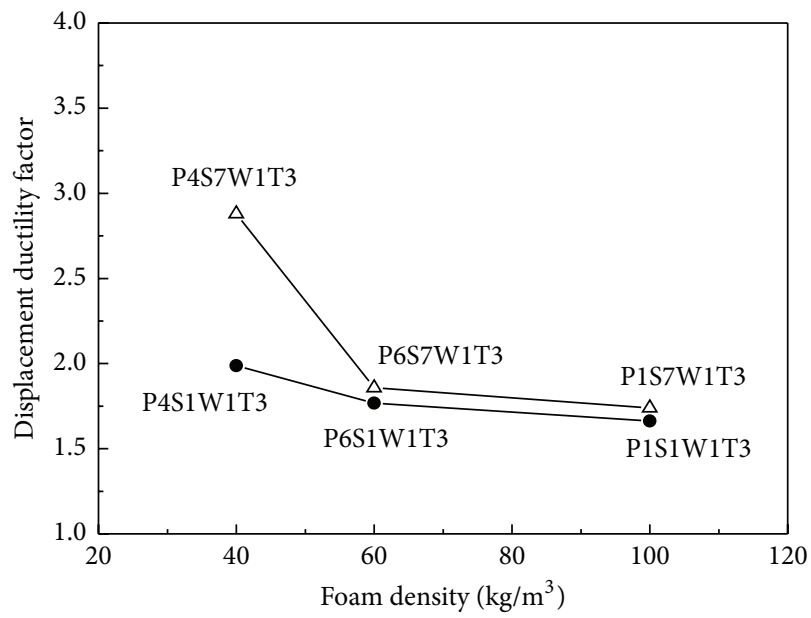

(b)

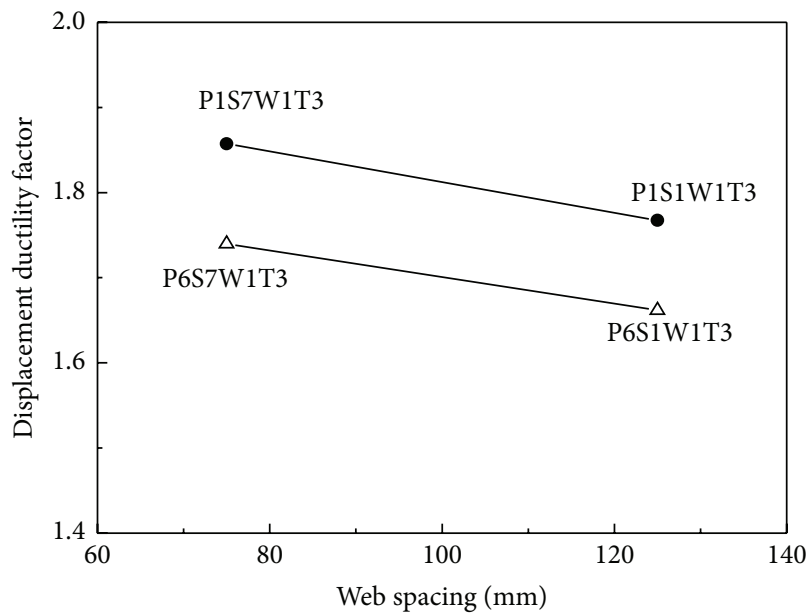

(d)

FIGURE 12: Displacement ductility factor: (a) the influence of face sheet thickness, (b) the influence of foam density, (c) the influence of web thickness, and (d) the influence of web thickness.

coefficients of GFFW decks were mainly affected by face sheet thickness, foam density, and the web thickness. The thinner face sheet, smaller foam density, and thinner web can provide better energy dissipation.

\section{Conclusions}

This paper presents the experimental study on the sandwich bridge decks with GFRP face sheets and a foam-web core loaded under two-way bending. The main findings of this study are summarized as follows:

(1) A new type of sandwich bridge decks with GFRP face sheets and a foam-web core was developed by means of vacuum assisted resin infusion process. These decks had the characteristics of high ultimate bending strength and initial bending stiffness.

(2) The experimental results show that, compared to the normal foam-core sandwich decks, a maximum of an approximately $657.1 \%$ increase in the ultimate bending strength of GFFW decks can be achieved due to the use of GFRP webs.

(3) The thicker GFRP face sheets, the smaller web spacing, the larger foam density, and the thicker GFRP webs can significantly enhance the ultimate bending strength and initial bending stiffness of GFFW decks. But the displacement ductility of GFFW decks can be affected by face sheet thickness slightly.

(4) The test results indicated that the displacement ductility of GFFW decks was mainly affected by the face sheet thickness, foam density, and web thickness, while the displacement ductility of GFFW decks decreased with the increase in web spacing slightly.

(5) The test results demonstrated that the energy ductility coefficient of GFFW decks decreased with the increase in face sheet thickness, foam density, and web thickness, while the energy ductility coefficient was not mainly affected by the web spacing. 


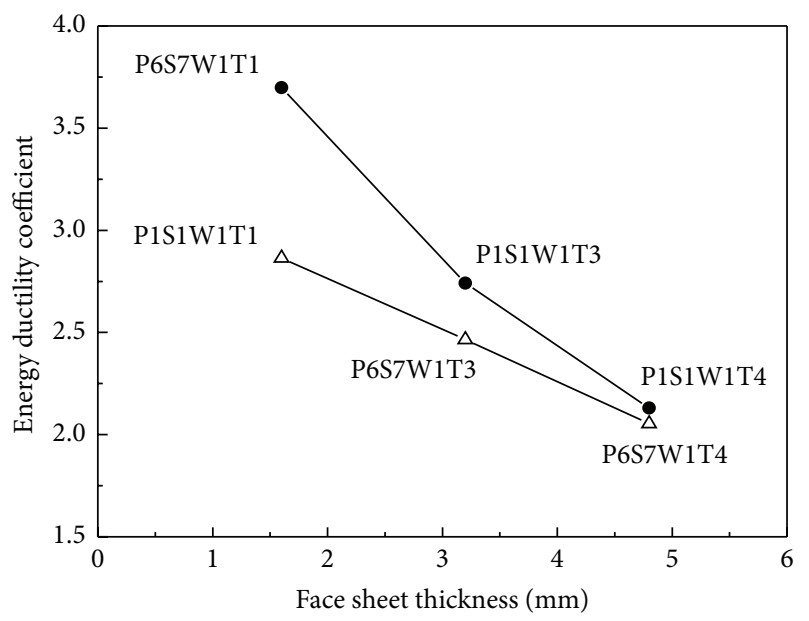

(a)

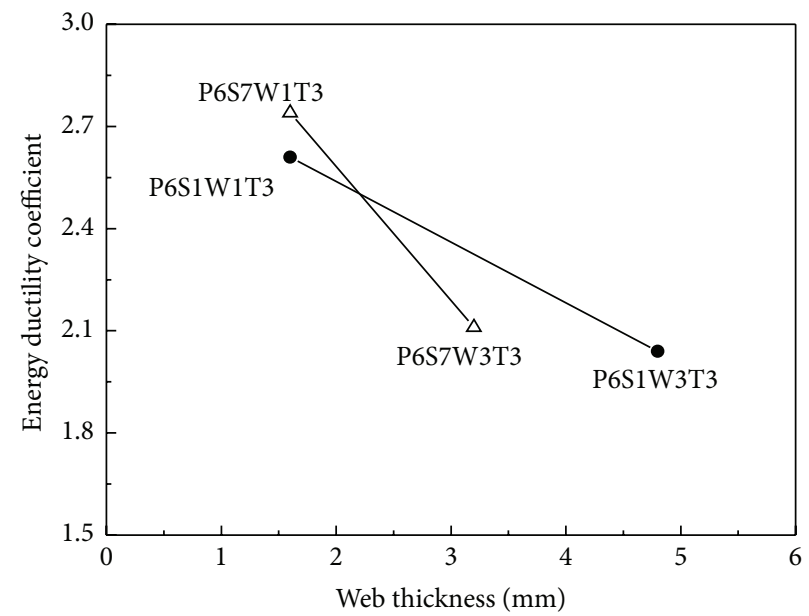

(c)

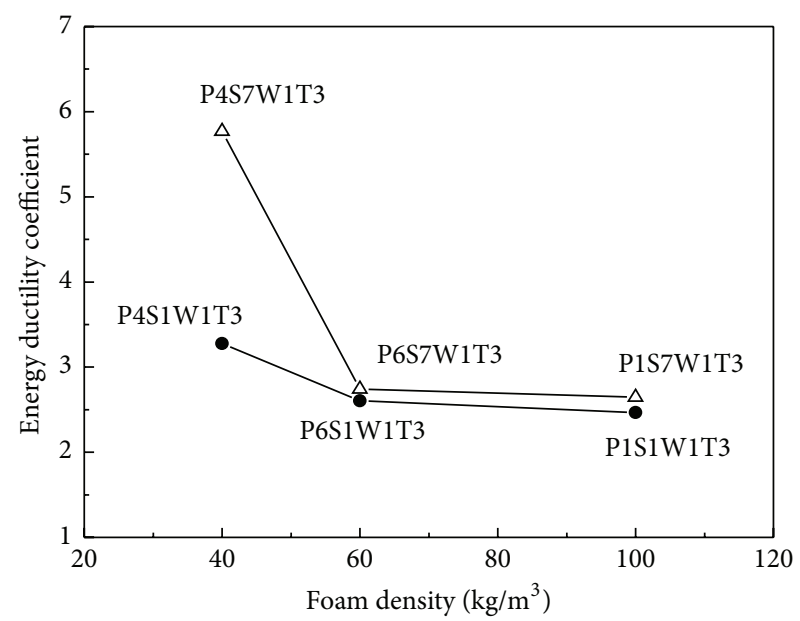

(b)

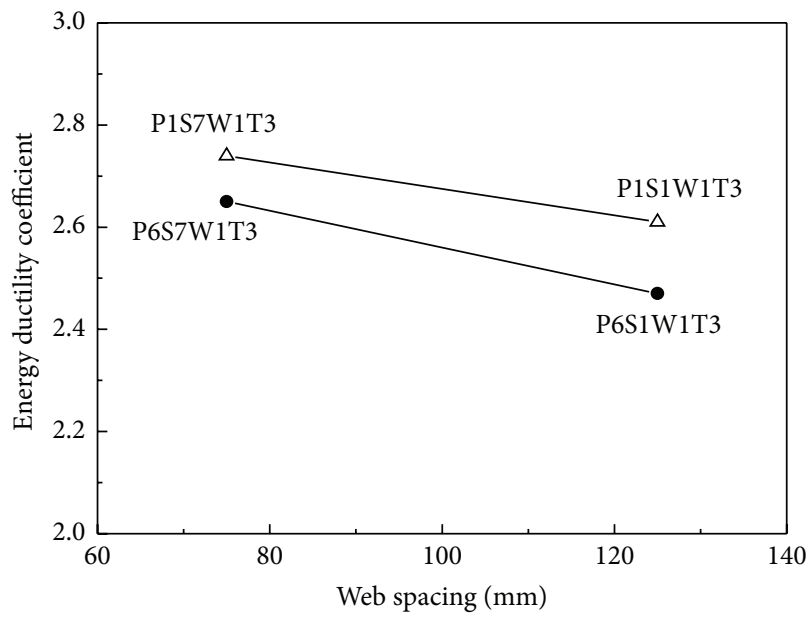

(d)

FIGURE 13: Energy ductility coefficient: (a) the influence of face sheet thickness, (b) the influence of foam density, (c) the influence of web thickness, and (d) the influence of web thickness.

(6) This new type of sandwich bridge decks with GFRP face sheets and a foam-web core is still under development; the corresponding numerical and analytical model will be developed to calculate the ultimate bending strength and deflection, and the minimum weight design procedure will also be proposed after carrying out more tests and simulation of GFFW decks.

\section{Conflict of Interests}

The authors declare that there is no conflict of interests regarding the publication of this paper.

\section{Acknowledgments}

The research described here was supported by the National Natural Science Foundation for the Youth of China (Grant no. 51408305) and Natural Science Foundation of Jiangsu Province (Grant no. BK20140946).

\section{References}

[1] T. Sharaf, W. Shawkat, and A. Fam, "Structural performance of sandwich wall panels with different foam core densities in oneway bending," Journal of Composite Materials, vol. 44, no. 19, pp. 2249-2263, 2010.

[2] J. Romanoff and P. Varsta, "Bending response of web-core sandwich beams," Composite Structures, vol. 73, no. 4, pp. 478487, 2006.

[3] J. Romanoff and P. Varsta, "Bending response of web-core sandwich plates," Composite Structures, vol. 81, no. 2, pp. 292302, 2007.

[4] A. Russo and B. Zuccarello, "Experimental and numerical evaluation of the mechanical behaviour of GFRP sandwich panels," Composite Structures, vol. 81, no. 4, pp. 575-586, 2007.

[5] C. A. Steeves and N. A. Fleck, "Collapse mechanisms of sandwich beams with composite faces and a foam core, loaded in three-point bending. Part I. Analytical models and minimum weight design," International Journal of Mechanical Sciences, vol. 46, no. 4, pp. 561-583, 2004. 
[6] C.-A. Steeves and N.-A. Fleck, "Collapse mechanisms of sandwich beams with composite faces and a foam core, loaded in three-point bending. Part II: experimental investigation and numerical modelling," International Journal of Mechanical Sciences, vol. 46, no. 4, pp. 585-608, 2004.

[7] V.-L. Tagarielli, N.-A. Fleck, and V.-S. Deshpande, "Collapse of clamped and simply supported composite sandwich beams in three-point bending," Composites B: Engineering, vol. 35, no. 68, pp. 523-534, 2004.

[8] E.-M. Reis, Characteristics of innovative 3-D FRP sandwich panels [Ph.D. thesis], North Carolina State University, Raleigh, NC, USA, 2005.

[9] E. M. Reis and S. H. Rizkalla, "Material characteristics of 3-D FRP sandwich panels," Construction and Building Materials, vol. 22, no. 6, pp. 1009-1018, 2008.

[10] G. Zi, B. M. Kim, Y. K. Hwang, and Y. H. Lee, "An experimental study on static behavior of a GFRP bridge deck filled with a polyurethane foam," Composite Structures, vol. 82, no. 2, pp. 257-268, 2008.

[11] G. Zi, B. M. Kim, Y. K. Hwang, and Y. H. Lee, "The static behavior of a modular foam-filled GFRP bridge deck with a strong web-flange joint," Composite Structures, vol. 85, no. 2, pp. 155-163, 2008.

[12] M. Dawood, E. Taylor, and S. Rizkalla, "Two-way bending behavior of 3-D GFRP sandwich panels with through-thickness fiber insertions," Composite Structures, vol. 92, no. 4, pp. 950963, 2010.

[13] Z.-M. Wu, W.-Q. Liu, L. Wang, H. Fang, and D. Hui, "Theoretical and experimental study of foam-filled lattice composite panels under quasi-static compression loading," Composites $B$ : Engineering, vol. 60, pp. 329-340, 2014.

[14] L. Wang, W.-Q. Liu, L. Wan, H. Fang, and D. Hui, "Mechanical performance of foam-filled lattice composite panels in fourpoint bending: experimental investigation and analytical modeling," Composites Part B: Engineering, vol. 67, pp. 270-279, 2014.

[15] L. Wang, W.-Q. Liu, H. Fang, and L. Wan, "Behavior of sandwich wall panels with GFRP face sheets and a foam-GFRP web core loaded under four-point bending," Journal of Composite Materials, vol. 49, no. 22, pp. 2765-2778, 2015.

[16] ASTM International, "Standard test method for tensile properties of polymer matrix composite materials," ASTM D3039/D3039M-08, ASTM International, West Conshohocken, $\mathrm{Pa}, \mathrm{USA}, 2008$.

[17] ASTM International, "Standard test method for compressive properties of rigid plastics," ASTM D695-10, ASTM International, West Conshohocken, Pa, USA, 2010.

[18] ASTM International, "Standard test method for flatwise compressive strength of sandwich cores," ASTM C365-03, ASTM International, West Conshohocken, Pa, USA, 2004.

[19] ASTM International, "Standard test method for shear properties for sandwich cores materials," ASTM C273/273M-07, ASTM International, West Conshohocken, Pa, USA, 2007. 

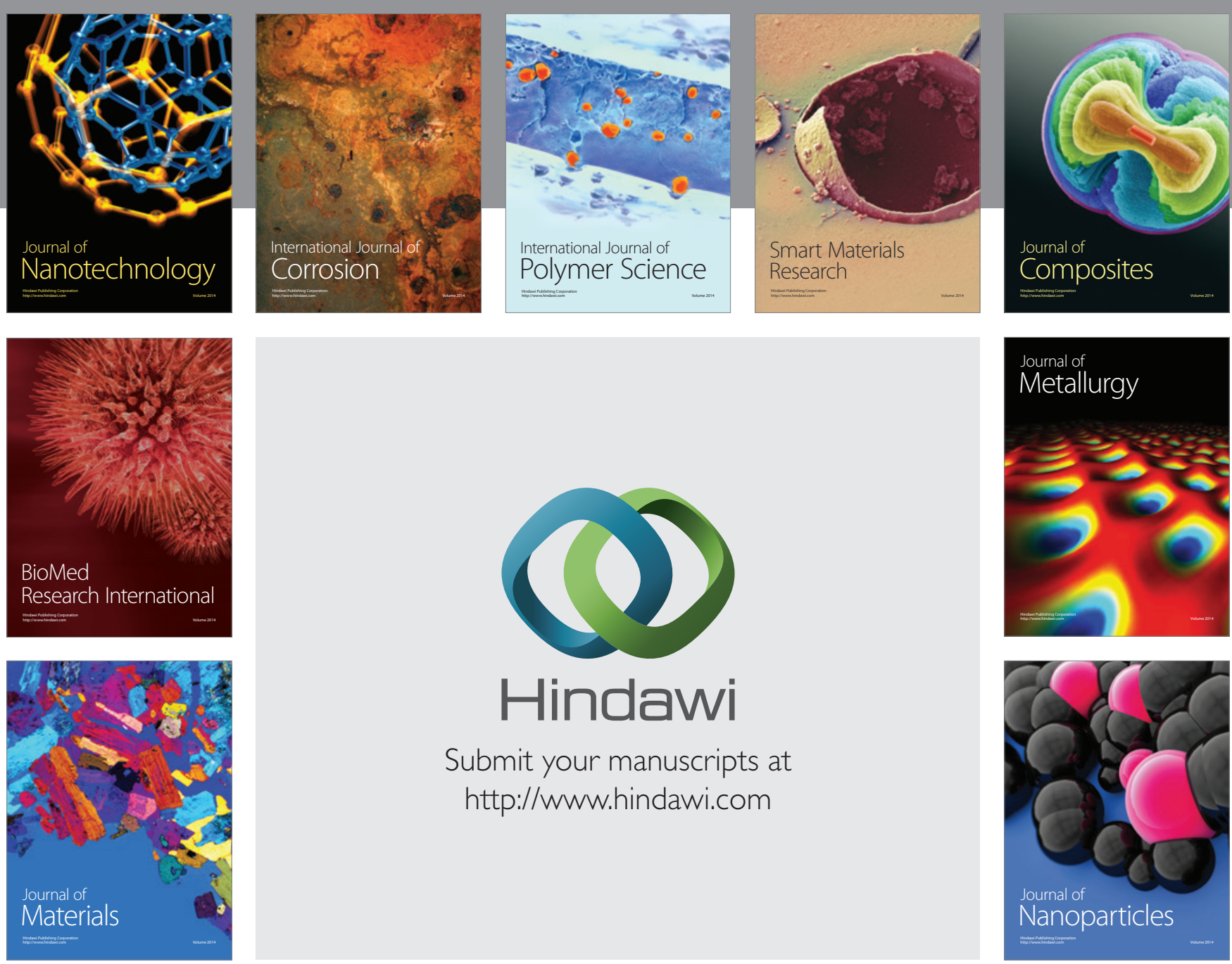

Submit your manuscripts at http://www.hindawi.com
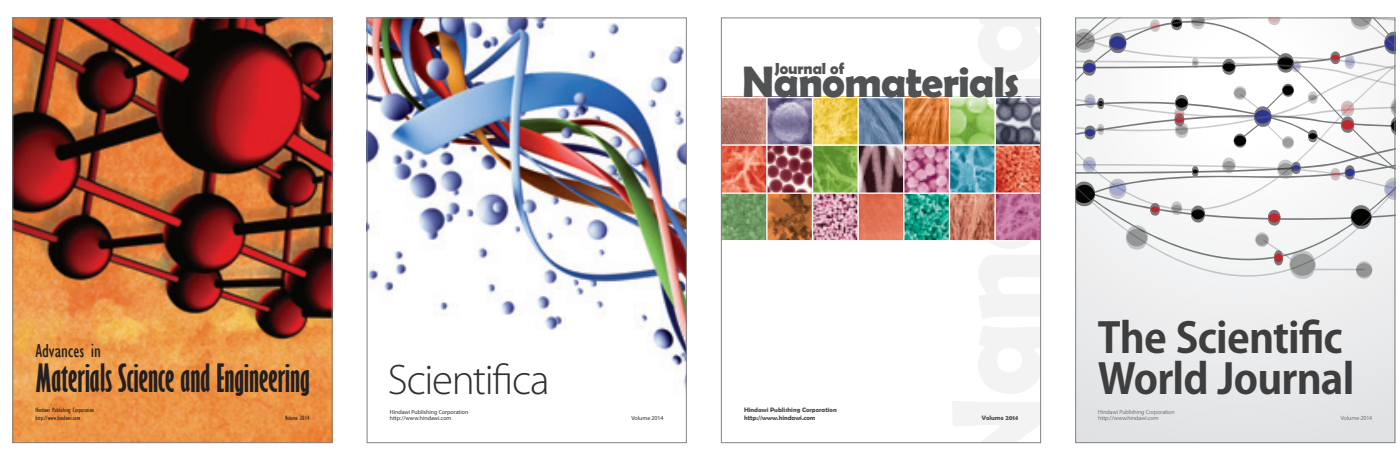

\section{The Scientific World Journal}
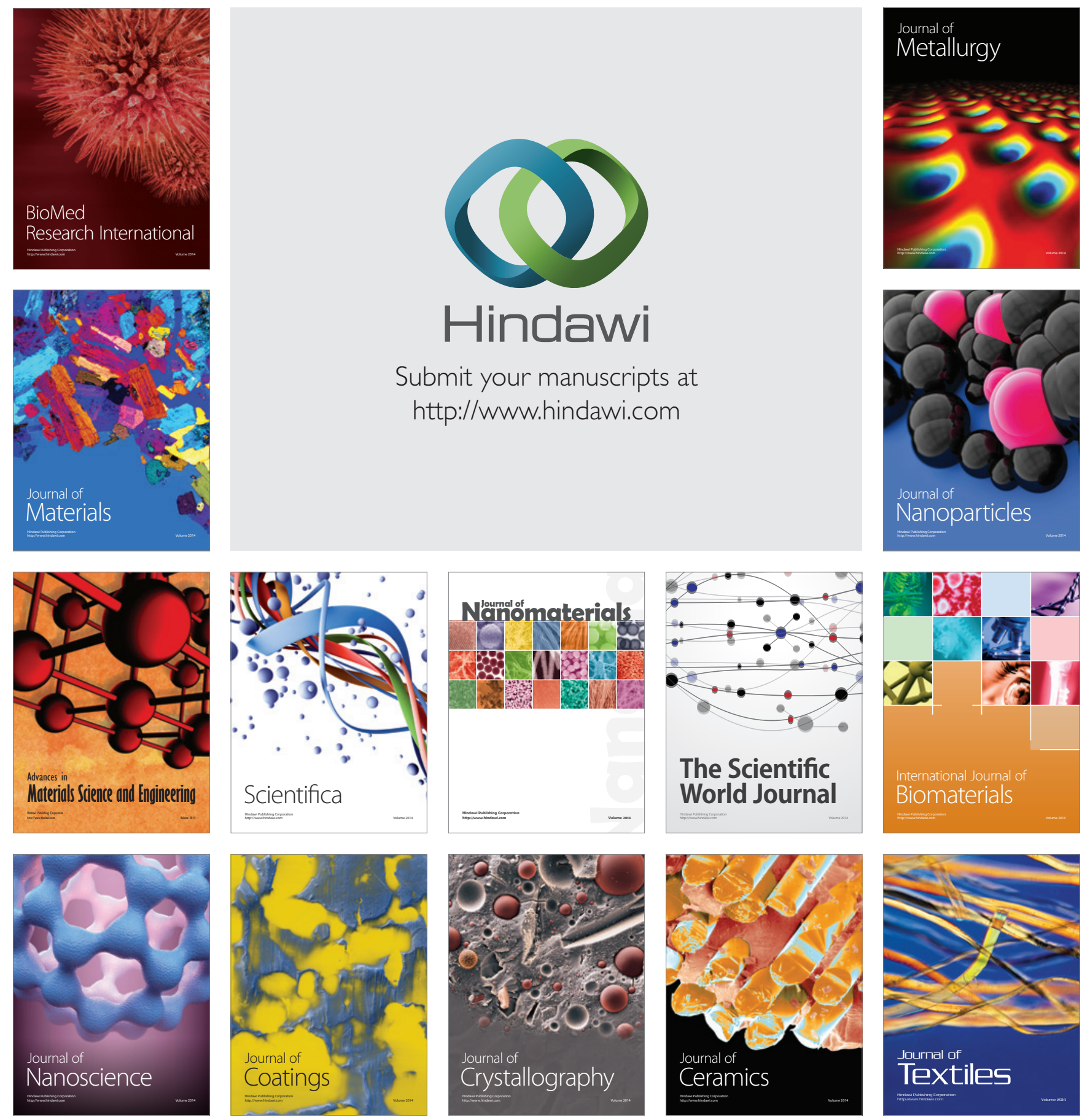